\title{
Association between first caesarean delivery and adverse outcomes in subsequent pregnancy: a retrospective cohort study
}

Hong-Tao Hu${ }^{1 \dagger}$, Jing-Jing $\mathrm{Xu}^{1+}$, Jing Lin ${ }^{1}$, Cheng $\mathrm{Li}^{1}$, Yan-Ting Wu${ }^{2}$, Jian-Zhong Sheng ${ }^{3}$, Xin-Mei Liu ${ }^{4,5^{*}}$ and He-Feng Huang $2,4,5^{*}$

\begin{abstract}
Background: Few studies have explored the association between a previous caesarean section (CS) and adverse perinatal outcomes in a subsequent pregnancy, especially in women who underwent a non-indicated CS in their first delivery. We designed this study to compare the perinatal outcomes of a subsequent pregnancy in women who underwent spontaneous vaginal delivery (SVD) or CS in their first delivery.
\end{abstract}

Methods: This retrospective cohort study included women who underwent singleton deliveries at the International Peace Maternity and Child Health Hospital from January 2013 to December 2016. Data on the perinatal outcomes of all the women were extracted from the medical records. Multivariate logistic regression was conducted to assessed the association between CS in the first delivery and adverse perinatal outcomes in the subsequent pregnancy.

Results: CS delivery in the subsequent pregnancy was more likely for women who underwent CS in their first birth than for women with previous SVD (97.3\% versus $13.2 \%)$. CS in the first birth was also associated with a significantly increased risk of adverse outcomes in the subsequent pregnancy, especially in women who underwent a nonindicated CS. Adverse perinatal outcomes included pregnancy-induced hypertension [adjusted odds ratio (OR), 95\% confidence interval (Cl): 2.20, 1.59-3.05], gestational diabetes mellitus (1.82, 1.57-2.11), gestational anaemia (1.27, 1 . 05-1.55), placenta previa $(3.18,2.15-4.71)$, placenta accreta $(2.75,1.75-4.31)$, and polyhydramnios $(2.60,1.57-4.31)$ in the mother and preterm delivery $(1.37,1.06-1.78)$, low birth weight $(3.78,2.07-6.90)$, macrosomia $(5.04,3.95-6.44)$, and neonatal jaundice $(1.72,1.39-2.14)$ in the baby.

Conclusions: CS in the first delivery markedly increases the risk of repeated CS and maternal-fetal complications in the subsequent pregnancy, especially in women with a non-indicated CS.

Keywords: Cohort, Pregnancy outcomes, Caesarean delivery, Subsequent pregnancy

\footnotetext{
* Correspondence: nanlilac@hotmail.com; huanghefg@sjtu.edu.cn

${ }^{+} \mathrm{Hong}$-Tao Hu and Jing-Jing Xu contributed equally to this work.

${ }^{4}$ Institute of Embryo-Fetal Original Adult Disease, Shanghai Key Laboratory

for Reproductive Medicine, School of Medicine, Shanghai Jiao Tong

University, Shanghai, China

${ }^{2}$ Department of Reproductive Medicine, International Peace Maternity and

Child Health Hospital, School of Medicine, Shanghai Jiao Tong University,

Shanghai, China

Full list of author information is available at the end of the article
}

(c) The Author(s). 2018 Open Access This article is distributed under the terms of the Creative Commons Attribution 4.0 International License (http://creativecommons.org/licenses/by/4.0/), which permits unrestricted use, distribution, and reproduction in any medium, provided you give appropriate credit to the original author(s) and the source, provide a link to the Creative Commons license, and indicate if changes were made. The Creative Commons Public Domain Dedication waiver (http://creativecommons.org/publicdomain/zero/1.0/) applies to the data made available in this article, unless otherwise stated. 


\section{Background}

The high prevalence of caesarean section (CS) is a global public health issue. According to a WHO statement in 1985, regional CS rates should not exceed $10-15 \%[1,2]$. However, the rate of CS has markedly increased from approximately 6 to $40 \%$ in low, medium and high income countries in the past three decades [3-6]. China has a high rate of CS as well as CS without medical indication $[4,6]$. Between 1988 and 2010, caesarean rates in all of China rose from 3.4 to $52.5 \%$, while urban rates increased from 10 to $57 \%$ [7, 8]. Maternal request and previous CS are the most common indications for $\mathrm{CS}$ in mainland China [9]. According to a large, cross-sectional study of 496,054 caesarean deliveries, the prevalence of primary non-indicated CS increased from $0.6 \%$ in $1993-$ 1995 to $21.3 \%$ in 2006-2010 [10]. Other studies have reported national rates of non-indicated CS ranging from 28.43 to $38.1 \%$ in China $[9,11]$. Prior CS is an important factor in the determination of a subsequent CS, which has led to overall high CS rates [6]. As implementation of China's 'two-child policy' has triggered the next baby boom, many women with a previous CS might require repeated CS in their subsequent deliveries $[9,12]$. Thus, the adverse outcomes in subsequent pregnancies for Chinese women with a previous CS must be further surveyed.

Although CS is accepted as a fairly safe procedure, and the overall rates of CS complications have decreased during the last decade [13], CS is still associated with an increased risk of maternal complications. According to recent data up to 2015, the WHO announced that CS rates higher than $10 \%$ were not associated with reductions in maternal and newborn mortality rates at the population level [2, 14, 15]. The WHO global survey indicated that caesarean delivery was positively associated with an increased risk of postpartum antibiotic use, maternal morbidity and mortality, and fetal and neonatal morbidity [3, 4]. Furthermore, prior CS was significantly associated with a deficit in subsequent fertility [16-19] and an increased risk of unexplained stillbirth in the subsequent pregnancy [20, 21]. Repeated CS was reported to increase maternal morbidity, including placenta accreta, reduced fetal growth, preterm delivery, pelvic pain, and adverse reproductive effects [22, 23]. However, few studies [24-27] of the Chinese population have explored the association between previous CS and adverse perinatal outcomes in a subsequent pregnancy, especially in women with a first non-indicated CS. Thus, we designed this study to compare the perinatal outcomes of subsequent pregnancies in women with a first spontaneous vaginal delivery to those with a CS.

\section{Methods}

\section{Data source}

The data for this study were obtained from the databases of the International Peace Maternity and Child Health Hospital. The perinatal database contains pregnancy, delivery, and pregnancy outcome data for all births submitted as paper copies of the delivery record or through an electronic extract in this hospital. Validation was performed on the data to check for errors and inconsistencies in documentation and coding. This study was performed in accordance with the declaration of Helsinki. Complications related to pregnancy and delivery, as well as related co-morbidities, were coded using criteria taken from the 9th and 10th revisions of the International Classification of Diseases (ICD-9 and -10).

\section{Study population}

In this retrospective study, we included all parous women who underwent a singleton delivery at the International Peace Maternity and Child Health Hospital from January 2013 to December 2016. Subjects with missing information on the previous mode of delivery, with multiple pregnancies in the first birth, or with parity over twice were excluded. To reduce heterogeneity of the study population, women were respectively excluded due to their foreign nationality and first instrumental vaginal delivery. We ultimately included women with spontaneous vaginal delivery (SVD group) and those with CS (CS group) in the first delivery into the analysis.

\section{Study design and definitions}

A retrospective cohort study design was used, and there were two groups according to the first mode of delivery in the cohorts. In consideration of the effects of indications for first CS on the next pregnancy, a subgroup analysis was performed between the previous SVD group and previous non-indicated CS group. Potential confounders were extracted, including birth place, nationality, insurance, marital status, age at second delivery, height, body mass index (BMI), education level, gravidity, and interpregnancy interval. Age was given in completed years at the time of delivery and was further subgrouped into $<25,25-29,30-34,35-39$, and $\geq$ 40 years. Height was classified into $<155$, 155-164.9, 165-174.9, and $\geq 175 \mathrm{~cm}$. BMI was calculated by dividing antenatal booking weight $(\mathrm{kg})$ by height squared $(\mathrm{m})$ and was then recoded into the following five categories: $<18.5,18.5$ to $24.9,25$ to 29.9 , and $\geq 30 \mathrm{~kg} / \mathrm{m}^{2}$. Educational level was given as the higher level of the couple, which was divided into five groups $(\leq 9,10-12,13-15$, and $\geq 16$ years). Interpregnancy interval $(<1,1-3,3-5$, $5-10$, and $\geq 10$ years) was defined as the time elapsed from the date of the first delivery to the date of subsequent conception adjusted by ultrasound with the unit 
of measurement recorded in years. In terms of outcomes at first birth, women with pregnancy-induced hypertension $(\mathrm{PIH})$, preeclampsia $(\mathrm{PE})$, gestational diabetes mellitus (GDM), preterm delivery, low birth weight (LBW), macrosomia, or stillbirths in the first birth were compared in groups to assess differences.

In the second pregnancy, the following outcomes were assessed: PIH (diastolic blood pressure $>90 \mathrm{mmHg}$ on two occasions $4 \mathrm{~h}$ apart or a single reading of > $110 \mathrm{mmHg}$ from 20 weeks gestation), PE (PIH and proteinuria $0.3 \mathrm{~g} / 24 \mathrm{~h}$ ) $[28,29]$, GDM (diagnosed using a 2-h, $75 \mathrm{~g}$ oral glucose tolerance test) [30], gestational anaemia (anaemia occurred in subsequent pregnancy, excluding haematological diseases and history of anaemia), gestational thyroid dysfunction (thyroid dysfunction existed during the subsequent pregnancy, excluding surgery history of the thyroid, prior diagnosis of thyroid diseases, and taking medicines that influence thyroid function), intrahepatic cholestasis of pregnancy (ICP), premature rupture of membranes (PROM, defined as rupture of fetal membranes at least $1 \mathrm{~h}$ prior to the onset of labour) [31], fetal distress, meconium-staining of the amniotic fluid, amniotic fluid volume (AFV), placental abruption and placenta previa (placental abruption was defined as premature separation of a normally implanted placenta from the uterus, while placenta previa was defined as implantation of the placenta over or near the internal opening of the cervix), placenta accreta (placenta accreta refers to the entire spectrum of conditions, including accreta, increta, and percreta, as well as to cases of clinically apparent morbidly adherent placenta) $[32,33]$, rupture of the uterus, antepartum haemorrhage $(\mathrm{APH})$, fetal growth restriction (FGR), abnormal fetal position, dystocia, antepartum fever, mode of delivery (spontaneous vaginal, instrumental, or CS) in subsequent pregnancy, postpartum haemorrhage (PPH; blood loss > $500 \mathrm{ml}$ for vaginal delivery, $>1000 \mathrm{ml}$ for caesarean), and puerperal infection. Neonatal outcomes included stillbirth (delivery of a dead baby at or after $24^{+0}$ weeks gestation), preterm $\left(24^{+0}\right.$ to $36^{+6}$ weeks of gestation), LBW (<2500 g), macrosomia ( $4000 \mathrm{~g})$, Apgar score at $1 \mathrm{~min}$, neonatal infection, neonatal death (death of a liveborn infant in the first 4 weeks of life), admission to a neonatal intensive care unit, neonatal respiratory distress syndrome (NRDS), transient tachypnea of newborn (TTN), neonatal jaundice, and birth injury.

The primary indications for CS were divided into 3 categories: maternal indications, fetal indications, and maternal request with no obstetric reasons. To clarify these indications, we divided caesarean deliveries into 2 categories, medically indicated or non-medically indicated [11]. Medically indicated CS included fetal distress; prolonged labour (dystocia); cephalopelvic disproportion; malpresentation; PE or eclampsia; haemolysis, elevated liver enzyme, and low platelets syndrome (HELLP); ICP; placental abruption; placenta praevia; scarred uterus; oligohydramnios; intrauterine infection; and suspected macrosomia. Non-medically indicated CS was defined as a primary CS done on maternal request without medical indication (CDMR) or a physician documented "social influence". These included: elderly primigravida as the only indication, a "precious" infant-defined as in vitro pregnancy or poor obstetric history, severe myopia, isolated PROM without fetal heart rate (FHR) abnormalities, request for concomitant myomectomy or ovarian cystectomy, or other factors (isolated chronic hypertension; gestational hypertension; diabetes mellitus without macrosomia).

\section{Statistical analyses}

Statistical analyses were performed using SPSS version 20 software (IBM, SPSS Statistics, Armonk, NY, USA). Descriptive statistics were reported as the means and standard deviations for continuous variables and percentages for categorical variables. Differences in demographics and first birth outcomes in the cohorts were assessed using the Pearson Chi-square test or Fisher's exact test. Odds ratios (ORs) with their 95\% confidence intervals (CIs) were calculated to evaluate the association between CS in the first delivery and perinatal outcomes in the subsequent pregnancy via univariate (unadjusted for covariates) and multivariate statistical methods (adjusted for potential confounders to ascertain that relationships were due to demographic characteristics or adverse obstetric events). Variables found to be statistically significant in univariate analysis and confirmed as a risk factor by published literature were entered into the multivariate logistic regression model. Statistical significance was set at $P<0.05$.

\section{Results}

In total, 59,831 singleton births were recorded in the International Peace Maternity and Child Health Hospital between January 2013 and December 2016, and 12,390 who had a delivery history were treated as potential subjects. After excluding 49 women with missing information on the previous mode of delivery, 21 women with multiple pregnancies in the first birth, 329 women with parity over twice, 136 women with foreign nationality, and 187 women with instrumental vaginal delivery in the first birth, 11,662 subjects were included into the final analysis (6240 in the SVD group and 5422 in the CS group). Among the 5422 women in the CS group, 3595 (66.3\%) women had medical indications for CS, and 1827 (33.7\%) women had no medical indications for CS in their first birth (Fig. 1).

The demographic characteristics among the groups are compared in Table 1. Significant differences were 
59831 women with singleton delivery between 2013 and 2016

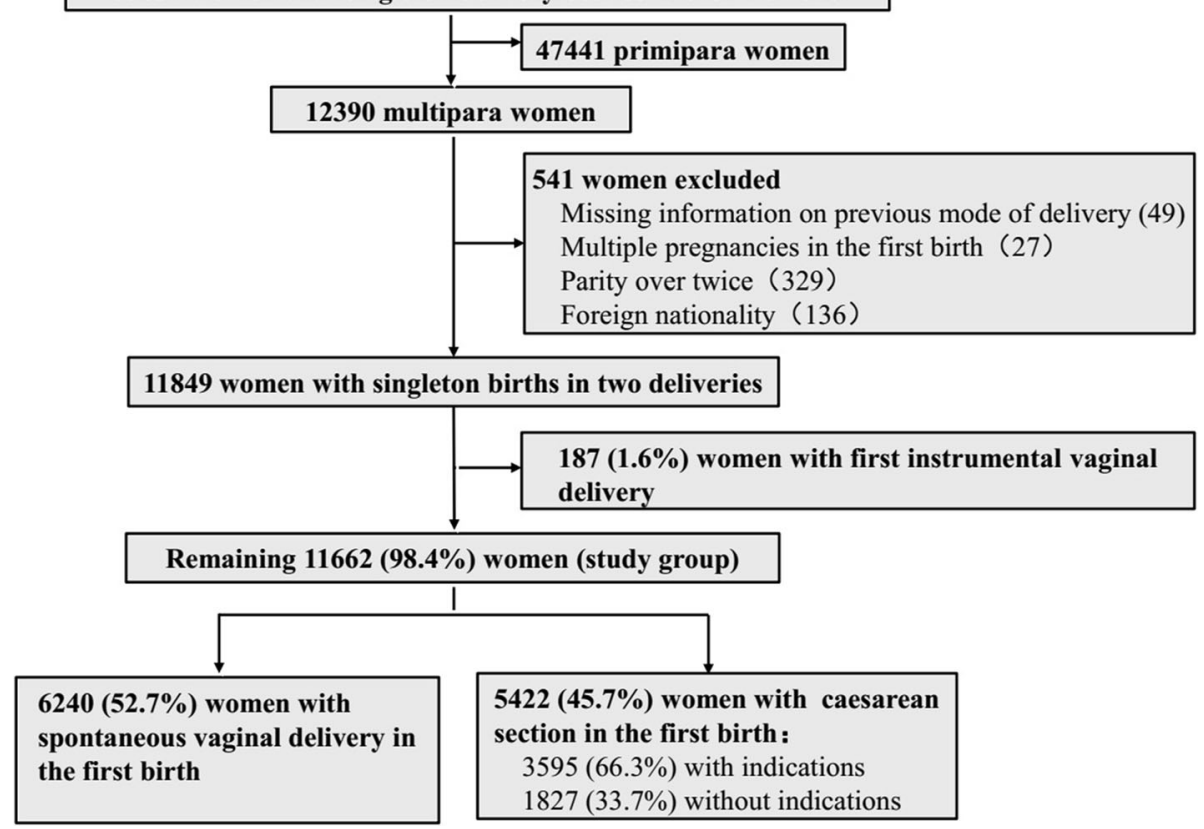

Fig. 1 Flow chart showing study population in cohorts

detected when comparing the CS group with the SVD group, including insurance, age at the subsequent delivery, height, maternal BMI, educational level, gravidity, and interpregnancy interval, while no differences in race were observed.

A comparison of the characteristics of the first birth is presented in Table 1. Women with an initial caesarean delivery were significantly more likely to have macrosomia (first CS group vs. first SVD group: $10.5 \%$ vs. $4.5 \%$; $P<0.001)$ in the first birth than those in the SVD group. In contrast, women with an initial CS were less likely to have preterm delivery (first CS group vs. first SVD group: $3.5 \%$ vs. $4.3 \% ; P=0.027$ ) and stillbirths (first CS group vs. first SVD group: $0.2 \%$ vs $1.0 \% ; \mathrm{P}<0.001$ ) in the first birth than those in the SVD group. There were no differences between the two groups in PIH, PE, GDM, or LBW in the first birth. However, there were significant differences in all first birth outcomes when comparing previous non-indicated CS to previous SVD.

Table 2 displays the associations between caesarean delivery in the first birth and maternal outcomes in the subsequent pregnancy, and the percentages of maternal outcomes are presented in Fig. 2a. After adjusting for potential confounders, women with previous CS were 1.38 times more likely to have PIH (95\% CI: 1.04-1.82), 1.15 times more likely to have GDM (95\% CI: $1.02-$ 1.29), 1.72 times more likely to have ICP (95\% CI: $1.04-$ 2.84), 2.50 times more likely to have polyhydramnios (95\% CI: 1.69-3.69), 2.11 times more likely to have placenta previa (95\% CI: 1.52-2.94), 2.11 times more likely to have placenta accreta (95\% CI: 1.47-3.04), 364.21 times more likely to choose caesarean delivery (95\% CI: 294.74-450.06), and 8.3 times more likely to suffer instrumental vaginal delivery (95\% CI: 4.41-15.6) in the next pregnancy. In contrast, the previous CS women were $66 \%$ less likely to have PROM (95\% CI: $0.30-0.39$ ), $67 \%$ less likely to suffer from fetal distress (95\% CI: $0.27-0.40), 51$ and $85 \%$ less likely to have moderate or severe meconium-staining of the amniotic fluid (95\% CI: $0.39-0.62$ and $0.11-0.19$, respectively), respectively, and $46 \%$ less likely to have antepartum fever (95\% CI: $0.33-$ 0.89 ) in the next pregnancy. Given the risk of the first CS with medical indications in the subsequent pregnancy, we performed a subgroup analysis of pregnancy outcomes in women who did not have indications in the first delivery. In this subgroup, women with previous non-indication CS were more likely to experience PIH (adjusted OR: 2.20; 95\% CI: 1.59-3.05), GDM (adjusted OR: 1.82; 95\% CI: 1.57-2.11), gestational anaemia (adjusted OR: 1.27 ; $95 \% \mathrm{CI}: 1.05-1.55)$, polyhydramnios (adjusted OR: 2.60; 95\% CI: 1.57-4.31), placenta previa (adjusted OR: 3.18; 95\% CI: 2.15-4.71), placenta accreta (adjusted OR: 2.75; 95\% CI: 1.75-4.31), and CS (adjusted OR: 694.16; 95\% CI: 468.45-1028.62). Seven women had uterine rupture in a subsequent pregnancy in the CS group, four of whom had a non-indicated CS in the first birth, but none of the women in the SVD group had uterine rupture.

Table 3 shows the association between previous caesarean delivery and neonatal outcomes in the subsequent 
Table 1 Maternal baseline characteristics and the first birth characteristics among women with previous SVD and those with previous CS and non-indicated CS

\begin{tabular}{|c|c|c|c|c|c|c|c|c|}
\hline & \multicolumn{2}{|c|}{ previous SVD $(n=6240)$} & \multicolumn{2}{|c|}{ previous CS $(n=5422)$} & \multirow[t]{2}{*}{$P$-value ${ }^{a}$} & \multicolumn{2}{|c|}{ previous non-indicated CS $(n=1827)$} & \multirow{2}{*}{$\begin{array}{l}P \text { - } \\
\text { value }^{b}\end{array}$} \\
\hline & $\bar{N}$ & $\%$ & $\mathrm{~N}$ & $\%$ & & $\mathrm{~N}$ & $\%$ & \\
\hline \multicolumn{9}{|l|}{ Baseline characteristics } \\
\hline \multicolumn{9}{|l|}{ Birth place } \\
\hline Shanghai & 4753 & $76.2 \%$ & 3991 & $73.6 \%$ & 0.001 & 1413 & $77.3 \%$ & 0.300 \\
\hline Out of Shanghai & 1487 & $23.8 \%$ & 1431 & $26.4 \%$ & & 414 & $22.7 \%$ & \\
\hline \multicolumn{9}{|l|}{ Race } \\
\hline Han & 6164 & $98.8 \%$ & 5353 & $98.7 \%$ & 0.791 & 1812 & $99.2 \%$ & 0.158 \\
\hline Minority & 76 & $1.2 \%$ & 69 & $1.3 \%$ & & 15 & $0.8 \%$ & \\
\hline \multicolumn{9}{|l|}{ Insurance } \\
\hline Public & 4239 & $67.9 \%$ & 3376 & $62.3 \%$ & $<0.001$ & 1099 & $60.2 \%$ & $<0.001$ \\
\hline Self-pay & 2001 & $32.1 \%$ & 2046 & $37.7 \%$ & & 728 & $39.8 \%$ & \\
\hline \multicolumn{9}{|l|}{ Marital status } \\
\hline Married/cohabitating & 6158 & $99.7 \%$ & 5366 & $99.5 \%$ & 0.093 & 1802 & $99.3 \%$ & 0.007 \\
\hline Not married/cohabitating & 17 & $0.3 \%$ & 25 & $0.5 \%$ & & 13 & $0.7 \%$ & \\
\hline \multicolumn{9}{|l|}{ Age at the second delivery } \\
\hline$<25$ years & 73 & $1.2 \%$ & 39 & $0.8 \%$ & $<0.001$ & 10 & $0.5 \%$ & $<0.001$ \\
\hline $25-29$ years & 1152 & $18.5 \%$ & 739 & $13.6 \%$ & & 228 & $12.5 \%$ & \\
\hline 30-34 years & 3055 & $48.9 \%$ & 2727 & $50.3 \%$ & & 917 & $50.2 \%$ & \\
\hline $35-39$ years & 1702 & $27.3 \%$ & 1693 & $31.2 \%$ & & 585 & $32.0 \%$ & \\
\hline$\geq 40$ years & 258 & $4.1 \%$ & 224 & $4.1 \%$ & & 87 & $4.8 \%$ & \\
\hline \multicolumn{9}{|l|}{ Height (cm) } \\
\hline$<155$ & 222 & $3.6 \%$ & 317 & $5.8 \%$ & $<0.001$ & 91 & $5.0 \%$ & 0.001 \\
\hline $155-164.9$ & 4013 & $64.3 \%$ & 3651 & $67.4 \%$ & & 1206 & $66.0 \%$ & \\
\hline $165-174.9$ & 1935 & $31.0 \%$ & 1419 & $26.2 \%$ & & 520 & $28.5 \%$ & \\
\hline$\geq 175$ & 70 & $1.1 \%$ & 35 & $0.6 \%$ & & 10 & $0.5 \%$ & \\
\hline \multicolumn{9}{|l|}{ Maternal BMI (Kg/m2) } \\
\hline$<18.5$ & 550 & $8.8 \%$ & 405 & $7.5 \%$ & $<0.001$ & 139 & $7.6 \%$ & $<0.001$ \\
\hline $18.5-24.9$ & 5313 & $85.2 \%$ & 4530 & $83.5 \%$ & & 1507 & $82.5 \%$ & \\
\hline $25-29.9$ & 338 & $5.4 \%$ & 423 & $7.8 \%$ & & 155 & $8.5 \%$ & \\
\hline$\geq 30$ & 39 & $0.6 \%$ & 64 & $1.2 \%$ & & 26 & $1.4 \%$ & \\
\hline \multicolumn{9}{|l|}{ Educational level (years) } \\
\hline$\leq 9$ & 266 & $4.4 \%$ & 205 & $3.9 \%$ & 0.042 & 35 & $2.0 \%$ & $<0.001$ \\
\hline $10-12$ & 494 & $8.2 \%$ & 469 & $9.0 \%$ & & 130 & $7.4 \%$ & \\
\hline $13-15$ & 1205 & $20.1 \%$ & 1119 & $21.6 \%$ & & 398 & $22.5 \%$ & \\
\hline$\geq 16$ & 4049 & $67.3 \%$ & 3399 & $65.5 \%$ & & 1203 & $68.1 \%$ & \\
\hline \multicolumn{9}{|l|}{ Gravidity } \\
\hline$\leq 2$ & 2984 & $47.8 \%$ & 2366 & $43.6 \%$ & $<0.001$ & 825 & $45.2 \%$ & 0.045 \\
\hline$\geq 3$ & 3256 & $52.2 \%$ & 3056 & $56.4 \%$ & & 1002 & $54.8 \%$ & \\
\hline \multicolumn{9}{|l|}{ Interpregnancy interval (years) } \\
\hline$<1$ & 431 & $7.0 \%$ & 88 & $1.6 \%$ & $<0.001$ & 29 & $1.6 \%$ & $<0.001$ \\
\hline $1-3$ & 1935 & $31.2 \%$ & 1350 & $25.0 \%$ & & 446 & $24.5 \%$ & \\
\hline $3-5$ & 1357 & $21.9 \%$ & 1521 & $28.2 \%$ & & 540 & $29.6 \%$ & \\
\hline
\end{tabular}


Table 1 Maternal baseline characteristics and the first birth characteristics among women with previous SVD and those with previous CS and non-indicated CS (Continued)

\begin{tabular}{|c|c|c|c|c|c|c|c|c|}
\hline & \multicolumn{2}{|c|}{ previous SVD $(n=6240)$} & \multicolumn{2}{|c|}{ previous CS $(n=5422)$} & \multirow[t]{2}{*}{$P$-value ${ }^{a}$} & \multicolumn{2}{|c|}{ previous non-indicated CS $(n=1827)$} & \multirow{2}{*}{$\begin{array}{l}P- \\
\text { value }^{b}\end{array}$} \\
\hline & $\bar{N}$ & $\%$ & $\bar{N}$ & $\%$ & & $\bar{N}$ & $\%$ & \\
\hline $5-10$ & 1816 & $29.3 \%$ & 1957 & $36.2 \%$ & & 665 & $36.5 \%$ & \\
\hline$\geq 10$ & 657 & $10.6 \%$ & 485 & $9.0 \%$ & & 142 & $7.8 \%$ & \\
\hline \multicolumn{9}{|c|}{ First birth characteristics } \\
\hline \multicolumn{9}{|l|}{$\mathrm{PIH}$} \\
\hline Yes & 109 & $1.7 \%$ & 103 & $1.9 \%$ & 0.538 & 65 & $3.6 \%$ & $<0.001$ \\
\hline No & 6131 & $98.3 \%$ & 5319 & $98.1 \%$ & & 1762 & $96.4 \%$ & \\
\hline \multicolumn{9}{|l|}{ PE } \\
\hline Yes & 81 & $1.3 \%$ & 90 & $1.7 \%$ & 0.105 & 40 & $2.2 \%$ & 0.006 \\
\hline No & 6159 & $98.7 \%$ & 5332 & $98.3 \%$ & & 1787 & $97.8 \%$ & \\
\hline \multicolumn{9}{|l|}{ GDM } \\
\hline Yes & 415 & $6.7 \%$ & 378 & $7.0 \%$ & 0.492 & 159 & $8.7 \%$ & 0.003 \\
\hline No & 5825 & $93.3 \%$ & 5044 & $93.0 \%$ & & 1668 & $91.3 \%$ & \\
\hline \multicolumn{9}{|c|}{ Stillbirths } \\
\hline Yes & 61 & $1.0 \%$ & 10 & $0.2 \%$ & $<0.001$ & 0 & $0.0 \%$ & $<0.001$ \\
\hline No & 6179 & $99.0 \%$ & 5412 & $99.8 \%$ & & 1827 & $100.0 \%$ & \\
\hline \multicolumn{9}{|l|}{ LBW } \\
\hline Yes & 144 & $2.3 \%$ & 144 & $2.7 \%$ & 0.227 & 26 & $1.4 \%$ & 0.021 \\
\hline No & 6096 & $97.7 \%$ & 5278 & $97.3 \%$ & & 1801 & $98.6 \%$ & \\
\hline \multicolumn{9}{|c|}{ Macrosomia } \\
\hline Yes & 279 & $4.5 \%$ & 572 & $10.5 \%$ & $<0.001$ & 211 & $11.5 \%$ & $<0.001$ \\
\hline No & 5961 & $95.5 \%$ & 4850 & $89.5 \%$ & & 1616 & $88.5 \%$ & \\
\hline \multicolumn{9}{|c|}{ Preterm delivery } \\
\hline Yes & 266 & $4.3 \%$ & 188 & $3.5 \%$ & 0.027 & 16 & $0.9 \%$ & $<0.001$ \\
\hline No & 5974 & $95.7 \%$ & 5234 & $96.5 \%$ & & 1811 & $99.1 \%$ & \\
\hline
\end{tabular}

SVD spontaneous vaginal delivery, CS caesarean section, $B M I$ body mass index, $P I H$ pregnancy-induced hypertension, $P E$ preeclampsia, GDM gestational diabetes mellitus, $L B W$ low birth weight

${ }^{a}$ Comparison between previous CS and previous SVD

${ }^{\mathrm{b}}$ Comparison between previous non-indicated CS and previous SVD

pregnancy, and the percentages of neonatal outcomes are displayed in Fig. 2b. After adjusting for potential confounders, previous CS women were 1.37 times more likely to have preterm delivery (95\% CI: 1.14-1.66), 4.25 times more likely to have a baby with LBW (95\% CI: 2.73-6.62), 4.79 times more likely to have macrosomia (95\% CI: 3.94-5.83), and 1.39 times more likely to have their baby admitted to a neonatal unit (95\% CI: 1.161.65) compared with women who had a first SVD. Babies with TTN (adjusted OR: 1.93; 95\% CI: 1.33-2.81) were more common in women with a first CS, as were neonatal jaundice (adjusted OR: 1.72; 95\% CI: 1.392.14). However, there were no differences in stillbirth or neonatal death in the subsequent pregnancy between the previous CS and SVD groups (95\% CI: $0.27-2.18$ and 0.34-13.74, respectively). Given the risk of the first CS with medical indications in the subsequent pregnancy, we performed a subgroup analysis of neonatal outcomes in women who did not have indications in the first delivery. In this subgroup, women with previous non-indication CS were 1.37 times more likely to have preterm delivery (95\% CI: 1.06-1.78), 3.78 times more likely to have a baby with LBW (95\% CI: 2.07-6.90), 5.04 times more likely to have macrosomia (95\% CI: 3.95-6.44), and 1.58 times more likely to have a baby with neonatal jaundice (95\% CI: 1.17-2.13) than women in the SVD group.

\section{Discussion}

Main findings

Our results indicate that having a CS in the first singleton pregnancy is associated with an increased risk of adverse maternal and neonatal outcomes in subsequent singleton pregnancy in comparison to an initial SVD. The outcomes included a higher risk of PIH, GDM, ICP, polyhydramnios, placental previa, placental accreta, 
Table 2 Association between previous caesarean delivery and maternal outcomes in the subsequent pregnancy

\begin{tabular}{|c|c|c|c|c|c|c|c|c|c|c|}
\hline \multirow[t]{2}{*}{ Maternal outcomes } & \multicolumn{2}{|c|}{$\begin{array}{l}\text { previous } \\
\text { SVD }(n= \\
6240)\end{array}$} & \multicolumn{2}{|c|}{$\begin{array}{l}\text { previous } \\
\mathrm{CS}(n=5422)\end{array}$} & \multirow[t]{2}{*}{$\begin{array}{l}\text { Crude OR1 } \\
(95 \% \mathrm{Cl})\end{array}$} & \multirow[t]{2}{*}{$\begin{array}{l}\text { Model } 1 \text { Adjusted } \\
\text { OR1 (95\% Cl) }\end{array}$} & \multicolumn{2}{|c|}{$\begin{array}{l}\text { previous } \\
\text { nonindicated } \\
\operatorname{CS}(n=1827)\end{array}$} & \multirow[t]{2}{*}{$\begin{array}{l}\text { Crude OR2 } \\
(95 \% \mathrm{Cl})\end{array}$} & \multirow[t]{2}{*}{$\begin{array}{l}\text { Model } 2 \text { Adjusted } \\
\text { OR2 (95\% Cl) }\end{array}$} \\
\hline & $\mathrm{N}$ & $\%$ & $\mathrm{~N}$ & $\%$ & & & $\mathrm{~N}$ & $\%$ & & \\
\hline $\mathrm{PIH}$ & 99 & $1.6 \%$ & 131 & $2.4 \%$ & $1.54(1.18-2.00)$ & $1.38(1.04-1.82)^{a}$ & 75 & $4.1 \%$ & $2.66(1.96-3.60)$ & $2.20(1.59-3.05)^{d}$ \\
\hline PE & 84 & $1.3 \%$ & 90 & $1.7 \%$ & $1.24(0.92-1.67)$ & $1.22(0.88-1.69)^{a}$ & 34 & $1.9 \%$ & $1.39(0.93-2.08)$ & $1.24(0.79-1.94)^{d}$ \\
\hline GDM & 705 & $11.3 \%$ & 736 & $13.6 \%$ & $1.23(1.10-1.38)$ & $1.15(1.02-1.29)^{\mathrm{a}}$ & 371 & $20.3 \%$ & $2.00(1.74-2.30)$ & $1.82(1.57-2.11)^{d}$ \\
\hline Gestational anaemia & 455 & $7.3 \%$ & 458 & $8.4 \%$ & $1.17(1.03-1.34)$ & $1.13(0.98-1.30)$ & 166 & $9.1 \%$ & $1.27(1.06-1.53)$ & $1.27(1.05-1.55)^{d}$ \\
\hline $\begin{array}{l}\text { Gestational thyroid } \\
\text { disease }\end{array}$ & 256 & $4.1 \%$ & 223 & $4.1 \%$ & $1.01(0.84-1.20)$ & $1.03(0.85-1.24)$ & 64 & $3.5 \%$ & $0.85(0.64-1.12)$ & $0.86(0.65-1.16)^{d}$ \\
\hline ICP & 29 & $0.5 \%$ & 43 & $0.8 \%$ & $1.71(1.07-2.75)$ & $1.72(1.04-2.84)$ & 14 & $0.8 \%$ & $1.65(0.87-3.14)$ & $1.65(0.84-3.23)^{d}$ \\
\hline PROM & 1217 & $19.5 \%$ & 445 & $8.2 \%$ & $0.37(0.33-0.41)$ & $0.34(0.30-0.39)$ & 140 & $7.7 \%$ & $0.34(0.29-0.41)$ & $0.32(0.26-0.39)^{d}$ \\
\hline fetal distress & 493 & $7.9 \%$ & 159 & $2.9 \%$ & $0.35(0.29-0.42)$ & $0.33(0.27-0.40)$ & 55 & $3.0 \%$ & $0.36(0.27-0.48)$ & $0.34(0.25-0.46)^{d}$ \\
\hline \multicolumn{11}{|c|}{ meconium-staining of the amniotic fluid } \\
\hline I degree & 58 & $0.9 \%$ & 50 & $0.9 \%$ & $0.91(0.62-1.33)$ & $0.94(0.63-1.40)$ & 17 & $0.9 \%$ & $0.91(0.53-1.57)$ & $0.97(0.56-1.70)^{d}$ \\
\hline II degree & 236 & $3.8 \%$ & 114 & $2.1 \%$ & $0.51(0.41-0.64)$ & $0.49(0.39-0.62)$ & 33 & $1.8 \%$ & $0.44(0.30-0.63)$ & $0.39(0.26-0.57)^{d}$ \\
\hline III degree & 472 & $7.6 \%$ & 67 & $1.2 \%$ & $0.15(0.12-0.19)$ & $0.15(0.11-0.19)$ & 17 & $0.9 \%$ & $0.11(0.07-0.18)$ & $0.11(0.07-0.18)^{d}$ \\
\hline \multicolumn{11}{|l|}{ AFV } \\
\hline Oligohydramnios & 65 & $1.0 \%$ & 67 & $1.2 \%$ & $1.20(0.85-1.69)$ & $1.15(0.81-1.64)$ & 25 & $1.4 \%$ & $1.33(0.84-2.12)$ & $1.37(0.85-2.21)^{d}$ \\
\hline Polyhydramnios & 39 & $0.6 \%$ & 82 & $1.5 \%$ & $2.45(1.67-3.59)$ & $2.50(1.69-3.69)$ & 27 & $1.5 \%$ & $2.39(1.46-3.92)$ & $2.60(1.57-4.31)^{d}$ \\
\hline Placental abruption & 19 & $0.3 \%$ & 7 & $0.1 \%$ & $0.42(0.18-1.01)$ & $0.51(0.21-1.25)$ & 4 & $0.2 \%$ & $0.72(0.24-2.11)$ & $0.92(0.30-2.80)^{d}$ \\
\hline Placenta previa & 66 & $1.1 \%$ & 124 & $2.3 \%$ & $2.19(1.62-2.96)$ & $2.11(1.52-2.94)$ & 62 & $3.4 \%$ & $3.29(2.31-4.67)$ & $3.18(2.15-4.71)^{d}$ \\
\hline Placenta accreta & 53 & $0.8 \%$ & 104 & $1.9 \%$ & $2.28(1.64-3.18)$ & $2.11(1.47-3.04)$ & 45 & $2.5 \%$ & $2.95(1.97-4.40)$ & $2.75(1.75-4.31)^{d}$ \\
\hline Rupture of uterus & 0 & $0.0 \%$ & 7 & $0.1 \%$ & / & / & 4 & $0.2 \%$ & / & / \\
\hline $\mathrm{APH}$ & 61 & $1.0 \%$ & 59 & $1.1 \%$ & $1.11(0.78-1.60)$ & $0.96(0.64-1.43)$ & 25 & $1.4 \%$ & $1.41(0.88-2.25)$ & $1.13(0.66-1.93)^{d}$ \\
\hline FGR & 82 & $1.3 \%$ & 70 & $1.3 \%$ & $0.98(0.71-1.35)$ & $0.93(0.65-1.33)$ & 22 & $1.2 \%$ & $0.92(0.57-1.47)$ & $0.89(0.53-1.51)^{d}$ \\
\hline $\begin{array}{l}\text { Abnormal fetal } \\
\text { position }\end{array}$ & 193 & $3.1 \%$ & 194 & $3.6 \%$ & $1.16(0.95-1.42)$ & 1.09 (0.88-1.35) & 47 & $2.6 \%$ & $0.83(0.60-1.14)$ & $0.77(0.55-1.09)^{d}$ \\
\hline Dystocia & 197 & $3.2 \%$ & 196 & $3.6 \%$ & $1.15(0.94-1.41)$ & $1.09(0.88-1.34)$ & 46 & $2.5 \%$ & $0.79(0.57-1.10)$ & $0.73(0.52-1.04)^{d}$ \\
\hline Antepartum fever & 55 & $0.9 \%$ & 27 & $0.5 \%$ & $0.56(0.36-0.89)$ & $0.54(0.33-0.89)$ & 9 & $0.5 \%$ & $0.56(0.28-1.13)$ & $0.60(0.29-1.24)^{d}$ \\
\hline \multicolumn{11}{|l|}{ Mode of delivery } \\
\hline Caesarean section & 823 & $13.2 \%$ & 5278 & $97.3 \%$ & $\begin{array}{l}263.28(217.98- \\
318.01)\end{array}$ & $\begin{array}{l}364.21(294.74- \\
450.06)^{b}\end{array}$ & 1795 & $98.2 \%$ & $\begin{array}{l}375.49(261.30- \\
539.58)\end{array}$ & $\begin{array}{l}694.16(468.45- \\
1028.62)^{\mathrm{e}}\end{array}$ \\
\hline $\begin{array}{l}\text { Instrumental } \\
\text { delivery }\end{array}$ & 80 & $1.3 \%$ & 14 & $0.3 \%$ & $\begin{array}{l}7.18(3.97- \\
13.01)\end{array}$ & $8.30(4.41-15.60)^{b}$ & 1 & $0.1 \%$ & $\begin{array}{l}2.15(0.29- \\
15.96)\end{array}$ & $6.40(0.84-48.80)^{\mathrm{e}}$ \\
\hline $\mathrm{PPH}$ & 119 & $1.9 \%$ & 107 & $2.0 \%$ & $1.04(0.80-1.35)$ & $0.69(0.42-1.14)^{c}$ & 43 & $2.4 \%$ & $1.24(0.87-1.76)$ & $0.54(0.30-0.97)^{f}$ \\
\hline Puerperal infection & 16 & $0.3 \%$ & 15 & $0.3 \%$ & $1.08(0.53-2.19)$ & $0.99(0.35-2.83)^{c}$ & 4 & $0.2 \%$ & $0.85(0.29-2.56)$ & $0.50(0.12-2.19)^{f}$ \\
\hline
\end{tabular}

SVD spontaneous vaginal delivery, CS caesarean section, $P I H$ pregnancy-induced hypertension, $P E$ preeclampsia, GDM gestational diabetes mellitus, ICP intrahepatic cholestasis of pregnancy, $P R O M$ prelabour rupture of membranes, $A F V$ amniotic fluid volume, $A P H$ antepartum haemorrhage, $P P H$ postpartum haemorrhage, FGR fetal growth restriction, $O R$ odds radio, $\mathrm{Cl}$ confidence interval

Model 1: all ORs adjusted for birth place, insurance, age at the second delivery, height, maternal BMl, educational level, gravidity, interpregnancy interval

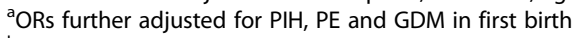

${ }^{b}$ ORs further adjusted for PIH, GDM, ICP, gestational anaemia, PROM and meconium-staining of the amniotic fluid, AFV, fetal distress, placental abruption, placenta previa, placenta accreta, rupture of uterus and antepartum fever

'ORs further adjusted for PIH, GDM, ICP, gestational anaemia, PROM and meconium-staining of the amniotic fluid, AFV, fetal distress, placental abruption, placenta previa, placenta accreta, rupture of uterus, antepartum fever and mode of delivery

Model 2: all ORs adjusted for insurance, marital status, age at the second delivery, height, maternal BMl, educational level, gravidity, interpregnancy interval ${ }^{\mathrm{d}}$ ORs further adjusted for PIH, PE and GDM in first birth

e ORs further adjusted for PIH, GDM, gestational anaemia, PROM, meconium-staining of the amniotic fluid, AFV, fetal distress, placenta previa, placenta accreta, rupture of uterus

fORs further adjusted for PIH, GDM, gestational anaemia, PROM and meconium-staining of the amniotic fluid, AFV, fetal distress, placenta previa, placenta accreta, rupture of uterus and mode of delivery 


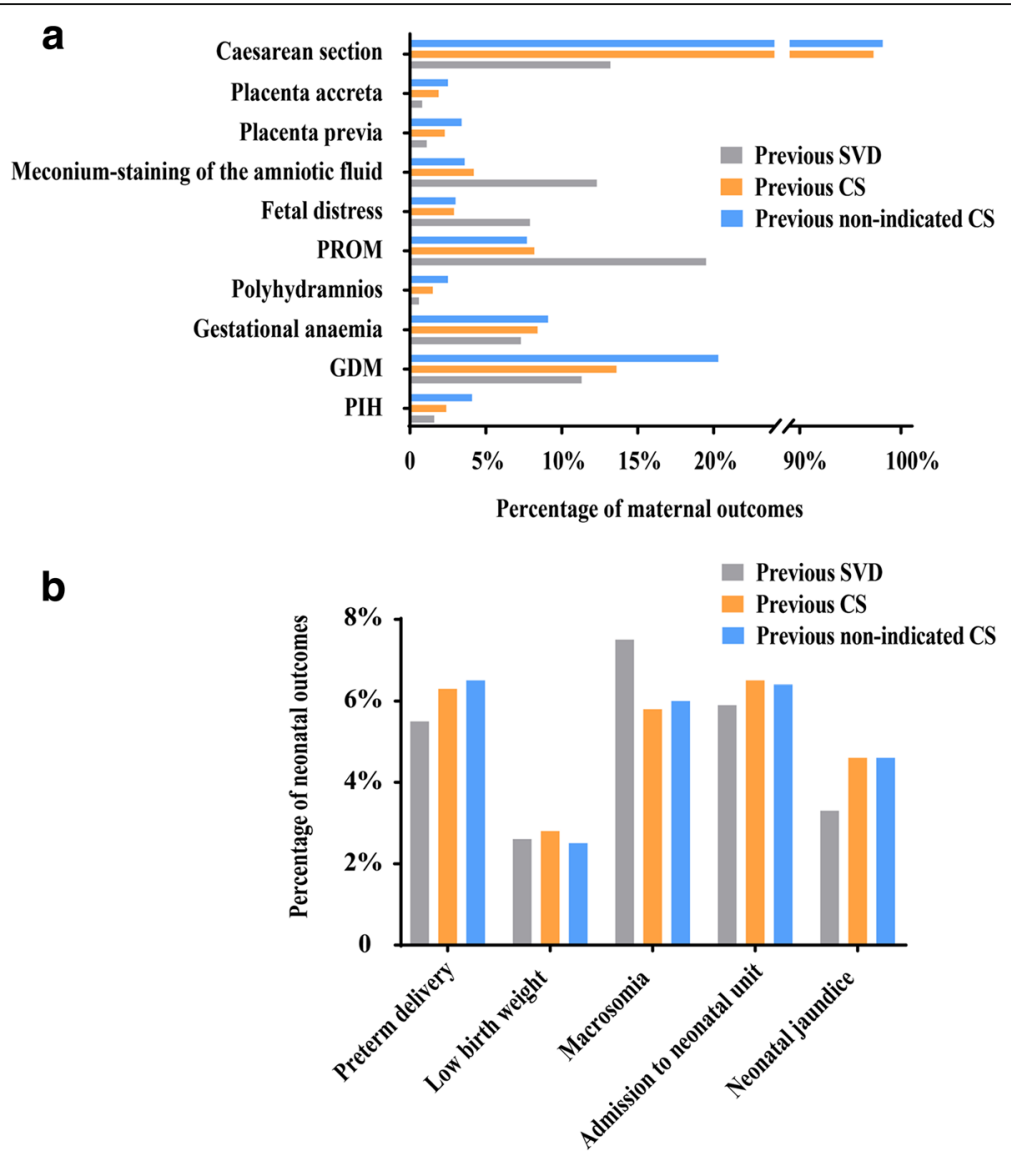

Fig. 2 Incidences of the main perinatal outcomes of the second births. a Percentages of the main maternal outcomes of the second births among the three groups. b Percentages of the main neonatal outcomes of second births among the three groups. SVD: spontaneous vaginal delivery; CS: caesarean section; PIH: pregnancy-induced hypertension; PE: preeclampsia; GDM: gestational diabetes mellitus; PROM: premature rupture of membranes

repeated caesarean delivery in the mother and preterm delivery, LBW, macrosomia, admission to a neonatal unit, TTN, and jaundice in the baby. Notably, in women without indications for CS in the first birth, there was still a significantly increased risk of PIH, GDM, polyhydramnios, placental previa, placental accrete, repeated caesarean delivery, and preterm, LBW, macrosomia, and neonatal jaundice.

\section{Strengths and limitations}

To the best of our knowledge, this is one of the few epidemiological studies exploring the association between CS in the first birth and perinatal complications in the subsequent pregnancy. There are several advantages to our study. First, the data analysed were taken from a geographically stable population and collected at the time of delivery from case notes, thereby minimizing selection and recall bias. Second, changes in clinical practice are unlikely to influence the findings, as the data of the two groups were recorded during the same period. Last but not least, we restricted our analyses to women with a second singleton birth, which eliminated potential confounding effects of parity and multiple gestations, and we also performed a subgroup analysis between previous non-indicated CS and previous SVD to avoid the risk of CS indications in the next pregnancy. Still, we should note that the presence of missing values and the retrospective nature of data collection may have biased the results to some extent. Briefly, the lack of adverse maternal outcomes in the first birth, such as PROM, placenta previa, and $\mathrm{APH}$, which may be risk factors that need to be adjusted to adverse outcomes in the next pregnancy, may have influenced the results. It was difficult to confirm the indications for CS from the retrospective data. Further prospective studies are required to reduce the information bias. Additionally, as the study was restricted to a single centre in Shanghai, the results may only be generalizable to that local area in China.

\section{Interpretation}

In our study population, $45.7 \%$ of the subjects experienced CS in the first singleton birth, and $33.7 \%$ of them 
Table 3 Association between previous caesarean delivery and neonatal outcomes in the subsequent pregnancy

\begin{tabular}{|c|c|c|c|c|c|c|c|c|c|c|}
\hline \multirow[t]{2}{*}{ Neonatal outcomes } & \multicolumn{2}{|c|}{$\begin{array}{l}\text { previous } \\
\text { SVD }(n= \\
6240)\end{array}$} & \multicolumn{2}{|c|}{$\begin{array}{l}\text { previous } \\
\mathrm{CS}(n= \\
5422)\end{array}$} & \multirow[t]{2}{*}{$\begin{array}{l}\text { Crude OR1 (95\% } \\
\text { Cl) }\end{array}$} & \multirow[t]{2}{*}{$\begin{array}{l}\text { Model } 1 \\
\text { Adjusted OR1 (95\% } \\
\text { Cl) }\end{array}$} & \multicolumn{2}{|c|}{$\begin{array}{l}\text { previous } \\
\text { nonindicated } \\
\mathrm{CS}(n=1827)\end{array}$} & \multirow[t]{2}{*}{$\begin{array}{l}\text { Crude OR2 (95\% } \\
\text { Cl) }\end{array}$} & \multirow[t]{2}{*}{$\begin{array}{l}\text { Model } 2 \\
\text { Adjusted OR2 (95\% } \\
\text { Cl) }\end{array}$} \\
\hline & $\mathrm{N}$ & $\%$ & $\mathrm{~N}$ & $\%$ & & & $\mathrm{~N}$ & $\%$ & & \\
\hline Stillbirths & 13 & $0.2 \%$ & 11 & $0.2 \%$ & $0.97(0.44-2.18)$ & $0.76(0.27-2.18)^{a}$ & 4 & $0.2 \%$ & $1.05(0.34-3.23)$ & $0.68(0.13-3.55)^{\mathrm{a}}$ \\
\hline Preterm delivery & 341 & $5.5 \%$ & 343 & $6.3 \%$ & $1.17(1.01-1.36)$ & $1.37(1.14-1.66)^{b}$ & 119 & $6.5 \%$ & $1.21(0.97-1.50)$ & $1.37(1.06-1.78)^{b}$ \\
\hline LBW & 162 & $2.6 \%$ & 151 & $2.8 \%$ & $1.08(0.86-1.35)$ & $4.25(2.73-6.62)^{c}$ & 46 & $2.5 \%$ & $0.97(0.70-1.35)$ & $3.78(2.07-6.90)^{c}$ \\
\hline Macrosomia & 466 & $7.5 \%$ & 317 & $5.8 \%$ & $0.77(0.66-0.89)$ & $4.79(3.94-5.83)^{d}$ & 110 & $6.0 \%$ & $0.79(0.64-0.98)$ & $5.04(3.95-6.44)^{d}$ \\
\hline Apgar at $1 \min <8$ & 79 & $1.3 \%$ & 74 & $1.4 \%$ & $1.08(0.78-1.49)$ & $1.13(0.77-1.66)$ & 25 & $1.4 \%$ & $1.08(0.69-1.70)$ & $1.18(0.69-2.01)$ \\
\hline Neonatal infection & 83 & $1.3 \%$ & 46 & $0.8 \%$ & $0.64(0.44-0.91)$ & $0.81(0.54-1.23)$ & 12 & $0.7 \%$ & $0.49(0.27-0.90)$ & $0.51(0.26-1.03)$ \\
\hline Neonatal death & 4 & $0.1 \%$ & 4 & $0.1 \%$ & $1.15(0.29-4.60)$ & $2.17(0.34-13.74)$ & 1 & $0.1 \%$ & $0.85(0.10-7.64)$ & $0.70(0.02-34.51)$ \\
\hline $\begin{array}{l}\text { Admission to neonatal } \\
\text { unit }\end{array}$ & 366 & $5.9 \%$ & 355 & $6.5 \%$ & $1.12(0.97-1.31)$ & $1.39(1.16-1.65)$ & 117 & $6.4 \%$ & $1.10(0.89-1.36)$ & $1.20(0.94-1.54)$ \\
\hline NRDS & 13 & $0.2 \%$ & 21 & $0.4 \%$ & $1.86(0.93-3.72)$ & $1.88(0.83-4.24)$ & 7 & $0.4 \%$ & $1.84(0.73-4.62)$ & $1.49(0.48-4.61)$ \\
\hline TTN & 71 & $1.1 \%$ & 91 & $1.7 \%$ & $1.48(1.09-2.03)$ & $1.93(1.33-2.81)$ & 28 & $1.5 \%$ & $1.35(0.87-2.10)$ & $1.55(0.93-2.58)$ \\
\hline Neonatal jaundice & 206 & $3.3 \%$ & 249 & $4.6 \%$ & $1.41(1.17-1.70)$ & $1.72(1.39-2.14)$ & 84 & $4.6 \%$ & $1.41(1.09-1.83)$ & $1.58(1.17-2.13)$ \\
\hline Birth injury & 16 & $0.3 \%$ & 9 & $0.2 \%$ & $0.65(0.29-1.49)$ & $0.85(0.35-2.06)$ & 4 & $0.2 \%$ & $0.85(0.29-2.56)$ & $0.85(0.25-2.85)$ \\
\hline
\end{tabular}

LBW low birth weight, NRDS neonatal respiratory distress syndrome, $T N$ transient tachypnea of newborn(TTN)

Model 1: all ORs adjusted for birth place, insurance, age at the second delivery, height, maternal BMI, educational level, gravidity, interpregnancy interval, PIH, GDM, ICP, gestational anaemia, PROM and meconium-staining of the amniotic fluid, AFV, fetal distress, placental abruption, placenta previa, placenta accreta, rupture of uterus, antepartum fever

Model 2: all ORs adjusted for insurance, marital status, age at the second delivery, height, maternal BMI, educational level, gravidity, interpregnancy interval, $\mathrm{PIH}$, GDM, gestational anaemia, PROM and meconium-staining of the amniotic fluid, AFV, fetal distress, placenta previa, placenta accreta, rupture of uterus

${ }^{a}$ ORs further adjusted for stillbirth at the first birth

${ }^{\mathrm{b}} \mathrm{ORs}$ further adjusted for preterm delivery at the first birth

'ORs further adjusted for LBW at the first birth

${ }^{\mathrm{d}}$ ORs further adjusted for macrosomia at the first birth

were non-indicated. The main reason for the high rate of CS and non-indicated CS may be attributed to the One Child Policy of the Chinese government during the period from 1978 to 2015. In the second singleton birth, the CS rate reached $52.3 \%$, which was approximately three times the proportion recommended by the WHO. This finding is consistent with studies reported previously in China [9,34]. We confirmed that some of the known baseline characteristics were associated with delivery mode, including maternal age, height, maternal BMI, educational level of the couples, gravidity, and interpregnancy interval, but these factors are not specific and were associated with a few of the adverse obstetric outcomes. Our present study findings suggest that CS in the first birth is linked with adverse maternal and neonatal outcomes in the next pregnancy. The effects of previous CS on the risk of placenta previa and placenta accreta are consistent with previous studies $[24,26,27$, 35-39]. These papers confirmed the association between placenta previa and previous CS and found that the ORs for placenta previa with one or more previous caesarean deliveries were 1.47-1.66, but the pooled OR of 2.2 from a meta-analysis [37] is consistent with the OR of 2.11 in our findings. Additionally, the risk of placenta accreta in our study was similar to results from previous research $[27,38]$. Possible mechanisms for placenta previa and accreta following previous CS suggested by previous researchers have included failure of placental apparent migration, impaired differential growth of the lower uterine segment, and deficient decidua basalis in the presence of previous surgery injury [24, 40-42]. In the present study, we focused on the adverse outcomes in second births, and our study represents a homogeneous sample affected by previous CS, which ruled out the influence of parity. Although there is disagreement on the association of previous CS with a higher risk of placenta abruption in the second pregnancy in prior studies $[24,26,27,36$, 38,39 , our study shows that previous CS does not increase the risk of placental abruption. Additionally, the incidence of uterine rupture $(0.1 \%)$ in the previous CS cohort in our study was less than that reported in prior studies [26, 27, 43-46], which may be attributed to the lower rate of trial of labour in women with a first CS in our country. The risks of APH and PPH in our study were not associated with the initial caesarean delivery, which is not consistent with previous studies $[26,47]$. Even in the subgroup analysis, there were no statistically significant differences for APH. However, the ORs were greater than one in the univariate analysis. There are several possible factors contributing to this finding: first, the missing information in the first birth may be confounding factors, and we cannot be certain whether they 
caused outcomes in the second birth; second, placental abruption, which is a primary cause of APH, was not increased in the first CS women in our study; third, the repeated CS reduced the occurrence of $\mathrm{PPH}$.

Our study seems to be the first to document the associations between previous CS history and increased risk of $\mathrm{PIH}, \mathrm{GDM}, \mathrm{ICP}$, and polyhydramnios in the next pregnancy. Especially in women without indications for a previous CS, the risks were much higher for PIH, GDM, and polyhydramnios. Similar research has shown the association between the first CS and the increased risk of PE $[27,48,49]$, but no differences were found in our study. Prior CS has been shown to be an important risk factor for subsequent complications, including placental vasculopathies [50], which may lead to a high risk of PIH. Pregnant women with PIH and/or GDM in the first pregnancy are highly susceptible to recurrence in the next pregnancy $[51,52]$. Thus, in our study, the high proportion of PIH and GDM in the first birth in the CS group may be a reason for the increased risk of PIH and GDM in the next pregnancy. Interestingly, when we regarded $\mathrm{PIH}$ and GDM in the first birth as confounding factors and adjusted for them, a high risk of PIH and GDM still existed in the next pregnancy for women with a first CS, especially in women without indications for the first CS. Moreover, uterine changes induced by prior CS may interfere with normal trophoblastic invasion and uteroplacental blood flow in subsequent pregnancies, resulting in abnormal placental function and subsequent gestational complications, including PIH and GDM [53, 54].

Compared to women with a prior SVD, the risks of PROM, fetal distress, meconium-staining of the amniotic fluid, and antepartum fever in the next birth were lower in women with an initial CS, which may be due to a missing confounding factor (PROM) in the first birth. Women with PROM were more likely to choose vaginal delivery in the first birth. Studies in the UK [31] and USA [55] showed that a PROM history was associated with a 6.6- to 20.6-fold increase in the risk of recurrent PROM. Furthermore, the decreased risk of fetal distress, meconium-staining of the amniotic fluid, and antepartum fever in women with primary CS in the second birth may also be related to the risks of these factors in the first birth.

The stillbirth rates were 2.0/1000 in both the previous CS group and previous SVD group, which was in accordance with preceding reports $[26,56]$, but there were no differences between the two groups in our research. Our findings on the effects of the first CS on the risk of preterm, LBW, macrosomia, admission to a neonatal unit, TTN of babies, and neonatal jaundice in the second pregnancy are consistent with previous studies $[26,43$, $57,58]$. There are few published studies providing evidence to support our findings; therefore, it is difficult to interpret the risk of caesarean delivery on these outcomes. Although there was a higher risk of admission to a neonatal unit for babies of first CS women in the next pregnancy, it did not increase their neonatal death rate. Additionally, in the subgroup analysis, there was no difference in admission to a neonatal unit and TTN in the two groups.

With implementation of the "two-child policy" in China, an increasing number of families will choose to raise two children. To control the overall CS rate, it is important to decrease the occurrence of primary CS, especially elective CS with no medical indications. These study findings will help women and clinical doctors in making choices and balancing the risks and benefits of a caesarean delivery in the first and subsequent births. The decision for an elective primary caesarean delivery should be carefully considered for its impact on future births.

\section{Conclusions}

CS in the first birth is associated with an increased risk of repeated caesarean delivery and adverse obstetric and perinatal outcomes in the following delivery, especially in women without CS indications. Clinicians might consider this information valuable when counselling women during pregnancy.

\section{Abbreviations}

AFV: Amniotic fluid volume; APH: Antepartum haemorrhage; BMI: Body mass index; Cl: Confidence interval; CS: Caesarean section; FGR: Fetal growth restriction; GDM: Gestational diabetes mellitus; HELLP: Haemolysis, elevated liver enzymes, and low platelets syndrome; ICP: Intrahepatic cholestasis of pregnancy; LBW: Low birth weight; NRDS: Neonatal respiratory distress syndrome; OR: Odds radio; PE: Preeclampsia; PIH: Pregnancy-induced hypertension; PPH: Postpartum haemorrhage; PROM: Premature rupture of membranes; SVD: Spontaneous vaginal delivery; TTN: Transient tachypnea of newborn

\section{Acknowledgements}

The authors would like to thank Lei Chen in International Peace Maternity and Child Health Hospital for his efforts in data collection and abstraction.

The authors are also grateful to Han Liu for helping with data analysis.

\section{Funding}

This work was supported by the International Cooperation Project of China and Canada NSFC (81661128010), The National Key Research and Development Program of China (No. 2017YFC1001303), National Natural Science Foundation of China (31471405), and Medical Crossover Foundation of Shanghai Jiao Tong University (YG2015MS42). The funding agencies had no role in study design, data collection and analysis, and decision to submit the article for publication.

\section{Availability of data and materials}

The datasets used and/or analysed during the current study are available from the corresponding author on reasonable request.

\section{Authors' contributions}

The study was conceived and designed by HFH XML and HTH. HHF had full access to all data in the study and take responsibility for the integrity of the data and accuracy of the data analysis. Validation was performed on the data to check for errors and inconsistencies in documentation and coding by $H T H$, JL and JJX. HTH and JJX performed the statistical analysis and wrote the manuscript. HFH, JZS, XML, YTW and CL revised the manuscript. All 
authors discussed the results and commented on the article. All authors read and approved the final manuscript.

\section{Ethics approval and consent to participate}

Ethical approval for this project was granted by the Ethics Committee of the International Peace Maternity and Child Health Hospital, School of Medicine, Shanghai Jiao Tong University. Being a retrospective study, consent to participate was waived.

\section{Consent for publication}

Not applicable.

\section{Competing interests}

The authors declare that they have no competing interests.

\section{Publisher's Note}

Springer Nature remains neutral with regard to jurisdictional claims in published maps and institutional affiliations.

\begin{abstract}
Author details
'Department of Obstetrics and Gynecology, International Peace Maternity and Child Health Hospital, School of Medicine, Shanghai Jiao Tong University, Shanghai, China. ${ }^{2}$ Department of Reproductive Medicine, International Peace Maternity and Child Health Hospital, School of Medicine, Shanghai Jiao Tong University, Shanghai, China. ${ }^{3}$ Department of Pathology and Pathophysiology, School of Medicine, Zhejiang University, Zhejiang, China. ${ }^{4}$ Institute of Embryo-Fetal Original Adult Disease, Shanghai Key Laboratory for Reproductive Medicine, School of Medicine, Shanghai Jiao Tong University, Shanghai, China. ${ }^{5}$ International Peace Maternity and Child Health Hospital, School of Medicine, Shanghai Jiao Tong University, 910 Hengshan Road, Shanghai 200030, China.
\end{abstract}

\section{Received: 31 January 2018 Accepted: 12 June 2018}

\section{Published online: 28 June 2018}

\section{References}

1. Appropriate technology for birth. Lancet (London, England). 1985;2(8452):436-7.

2. Betran AP, Torloni MR, Zhang JJ, Gulmezoglu AM, Section WHOWGC. WHO statement on caesarean section rates. BJOG. 2016;123(5):667-70.

3. Villar J, Valladares E, Wojdyla D, Zavaleta N, Carroli G, Velazco A, Shah A, Campodonico L, Bataglia V, Faundes A, et al. Caesarean delivery rates and pregnancy outcomes: the 2005 WHO global survey on maternal and perinatal health in Latin America. Lancet (London, England). 2006; 367(9525):1819-29.

4. Lumbiganon P, Laopaiboon M, Gulmezoglu AM, Souza JP, Taneepanichskul S, Ruyan P, Attygalle DE, Shrestha N, Mori R, Nguyen DH, et al. Method of delivery and pregnancy outcomes in Asia: the WHO global survey on maternal and perinatal health 2007-08. Lancet (London, England). 2010; 375(9713):490-9.

5. Betran AP, Ye J, Moller AB, Zhang J, Gulmezoglu AM, Torloni MR. The increasing trend in caesarean section rates: global, regional and National Estimates: 1990-2014. PLoS One. 2016;11(2):e0148343.

6. Vogel JP, Betrán AP, Vindevoghel N, Souza JP, Torloni MR, Zhang J, Tunçalp Ö, Mori R, Morisaki N, Ortiz-Panozo E, et al. Use of the Robson classification to assess caesarean section trends in 21 countries: a secondary analysis of two WHO multicountry surveys. Lancet Glob Health. 2015;3(5):e260-e270.

7. Feng $X \mathrm{~L}, \mathrm{Xu} \mathrm{L}, \mathrm{Guo} Y$, Ronsmans $\mathrm{C}$. Factors influencing rising caesarean section rates in China between 1988 and 2008. Bull World Health Organ. 2012:90(1):30-9. 39A

8. Hellerstein S, Feldman S, Duan T. China's 50\% caesarean delivery rate: is it too high? Bjog. 2015;122(2):160-4

9. Liu Y, Li G, Chen Y, Wang X, Ruan Y, Zou L, Zhang W. A descriptive analysis of the indications for caesarean section in mainland China. BMC Pregnancy Childbirth. 2014;14:410

10. Zhu YB, Li HT, Zhang YL, Li ZW, Zhang L, Liu JM. Secular trends of cesarean delivery and cesarean delivery on maternal request among primiparous women with singleton pregnancy in southern and northern China during 1993-2010. Zhonghua Yi Xue Za Zhi. 2012:92(25):1734-7.

11. Hou L, Hellerstein S, Vitonis A, Zou L, Ruan Y, Wang X, Zhang W. Cross sectional study of mode of delivery and maternal and perinatal outcomes in mainland China. PLoS One. 2017;12(2):e0171779.
12. Wang L, Xu X, Baker P, Tong C, Zhang L, Qi H, Zhao Y. Patterns and associated factors of caesarean delivery intention among expectant mothers in China: implications from the implementation of China's new National two-Child Policy. Int J Environ Res Public Health. 2016;13(7):686. https://doi. org/10.3390/ijerph13070686.

13. Creanga AA, Bateman BT, Butwick AJ, Raleigh L, Maeda A, Kuklina E, Callaghan WM. Morbidity associated with cesarean delivery in the United States: is placenta accreta an increasingly important contributor? Am J Obstet Gynecol. 2015;213((3):384):e381-11.

14. WHO Statement on caesarean section rates. Reprod Health Matters. 2015; 23(45):149-50.

15. Ye J, Zhang J, Mikolajczyk R, Torloni MR, Gulmezoglu AM, Betran AP. Association between rates of caesarean section and maternal and neonatal mortality in the 21st century: a worldwide population-based ecological study with longitudinal data. Bjog. 2016;123(5):745-53.

16. O'Neill SM, Khashan AS, Kenny LC, Kearney PM, Mortensen PB, Greene RA, Agerbo $\mathrm{E}$, Uldbjerg N, Henriksen TB. Time to subsequent live birth according to mode of delivery in the first birth. BJOG. 2015;122(9):1207-15.

17. Kjerulff $\mathrm{KH}$, Zhu J, Weisman CS, Ananth CV. First birth caesarean section and subsequent fertility: a population-based study in the USA, 2000-2008. Hum Reprod. 2013;28(12):3349-57.

18. Gurol-Urganci I, Bou-Antoun S, Lim CP, Cromwell DA, Mahmood TA, Templeton $A$, van der Meulen JH. Impact of caesarean section on subsequent fertility: a systematic review and meta-analysis. Hum Reprod. 2013;28(7):1943-52.

19. Gurol-Urganci I, Cromwell DA, Mahmood TA, van der Meulen JH, Templeton A. A population-based cohort study of the effect of caesarean section on subsequent fertility. Hum Reprod. 2014;29(6):1320-6.

20. Smith GCS, Pell JP, Bobbie R. Caesarean section and risk of unexplained stillbirth in subsequent pregnancy. Lancet. 2003;362(9398):1779-84.

21. AA Moraitis CO-W, AM Wood M, Fleming JP, Pell GCS. Smith: previous caesarean delivery and the risk of unexplained stillbirth: retrospective cohort study and meta-analysis. BJOG. 2015;122(11):1475.

22. Clark EA, Silver RM. Long-term maternal morbidity associated with repeat cesarean delivery. Am J Obstet Gynecol. 2011:205(6 Suppl):S2-10.

23. Cahill AG, Stamilio DM, Odibo AO, Peipert JF, Ratcliffe SJ, Stevens EJ, Sammel MD, Macones GA. Is vaginal birth after cesarean (VBAC) or elective repeat cesarean safer in women with a prior vaginal delivery? Am J Obstet Gynecol. 2006;195(4):1143-7.

24. Yang Q, Wen SW, Oppenheimer L, Chen XK, Black D, Gao J, Walker MC. Association of caesarean delivery for first birth with placenta praevia and placental abruption in second pregnancy. BJOG. 2007;114(5):609-13.

25. Colmorn LB, Krebs L, Klungsoyr K, Jakobsson M, Tapper AM, Gissler M, Lindqvist PG, Kallen K, Gottvall K, Bordahl PE, et al. Mode of first delivery and severe maternal complications in the subsequent pregnancy. Acta Obstet Gynecol Scand. 2017:96(9):1053-62.

26. Kennare R, Tucker G, Heard A, Chan A. Risks of adverse outcomes in the next birth after a first cesarean delivery. Obstet Gynecol. 2007:109(2 Pt 1):270-6.

27. Daltveit AK, Tollanes MC, Pihlstrom H, Irgens LM. Cesarean delivery and subsequent pregnancies. Obstet Gynecol. 2008:111(6):1327-34.

28. Ayorinde AA, Bhattacharya S. Inherited predisposition to preeclampsia: analysis of the Aberdeen intergenerational cohort. Pregnancy Hypertens. 2017:8:37-41.

29. Davey DA, MacGillivray I. The classification and definition of the hypertensive disorders of pregnancy. Am J Obstet Gynecol. 1988;158(4):892-8.

30. Yang S, Shi FT, Leung PC, Huang HF, Fan J. Low thyroid hormone in early pregnancy is associated with an increased risk of gestational diabetes mellitus. $J$ Clin Endocrinol Metab. 2016;101(11):4237-43.

31. Aris IM, Logan S, Lim C, Choolani M, Biswas A, Bhattacharya S. Preterm prelabour rupture of membranes: a retrospective cohort study of association with adverse outcome in subsequent pregnancy. BJOG. 2017; 124(11):1698-707

32. Silver RM. Abnormal Placentation: Placenta Previa, Vasa Previa, and Placenta Accreta. Obstet Gynecol. 2015;126(3):654-68.

33. Fitzpatrick KE, Sellers S, Spark P, Kurinczuk JJ, Brocklehurst P, Knight M. The management and outcomes of placenta accreta, increta, and percreta in the UK: a population-based descriptive study. BJOG. 2014;121(1):62-70. discussion 70-61

34. Liu Y, Wang X, Zou L, Ruan Y, Zhang W. An analysis of variations of indications and maternal-fetal prognosis for caesarean section in a tertiary hospital of Beijing: a population-based retrospective cohort study. Medicine (Baltimore). 2017;96(7):e5509. 
35. Taylor VM, Kramer MD, Vaughan TL, Peacock S. Placenta previa and prior cesarean delivery: how strong is the association? Obstet Gynecol. 1994;84(1):55-7.

36. Getahun D, Oyelese Y, Salihu HM, Ananth CV. Previous cesarean delivery and risks of placenta previa and placental abruption. Obstet Gynecol. 2006;107(4):771-8.

37. Gurol-Urganci I, Cromwell DA, Edozien LC, Smith GC, Onwere C, Mahmood TA, Templeton A, van der Meulen JH. Risk of placenta previa in second birth after first birth cesarean section: a population-based study and metaanalysis. BMC Pregnancy Childbirth. 2011;11:95.

38. Klar M, Michels KB. Cesarean section and placental disorders in subsequent pregnancies-a meta-analysis. J Perinat Med. 2014;42(5):571-83.

39. Lydon-Rochelle M, Holt VL, Easterling TR, Martin DP. First-birth cesarean and placental abruption or previa at second birth(1). Obstet Gynecol. 2001;97(5 Pt 1):765-9.

40. Sholapurkar SL. Increased incidence of placenta praevia and accreta with previous caesareans-a hypothesis for causation. J Obstet Gynaecol. 2013;33(8):806-9.

41. Clark SL, Koonings PP, Phelan JP. Placenta previa/accreta and prior cesarean section. Obstet Gynecol. 1985;66(1):89-92.

42. Paterson-Brown S, Singh C. Developing a care bundle for the management of suspected placenta accreta. Obstetrician Gynaecologist. 2010;12(1):21-7.

43. Taylor $L K$, Simpson JM, Roberts CL, Olive EC, Henderson-Smart DJ. Risk of complications in a second pregnancy following caesarean section in the first pregnancy: a population-based study. Med J Aust. 2005;183(10):515-9.

44. Guise JM, McDonagh MS, Osterweil P, Nygren P, Chan BK, Helfand M. Systematic review of the incidence and consequences of uterine rupture in women with previous caesarean section. BMJ (Clin Res ed). 2004:329(7456):19-25.

45. Spong CY, Landon MB, Gilbert S, Rouse DJ, Leveno K, Varner MW, Moawad AH, Simhan HN, Harper M, Wapner RJ, et al. Risk of uterine rupture and adverse perinatal outcome at term after cesarean delivery. Obstet Gynecol. 2007;110(4):801-7.

46. Motomura K, Ganchimeg T, Nagata C, Ota E, Vogel JP, Betran AP, Torloni MR, Jayaratne K, Jwa SC, Mittal S, et al. Incidence and outcomes of uterine rupture among women with prior caesarean section: WHO multicountry survey on maternal and newborn health. Sci Rep. 2017;7:44093.

47. Iyoke CA, Ugwu GO, Ezugwu FO, Lawani OL, Onah HE. Risks associated with subsequent pregnancy after one caesarean section: a prospective cohort study in a Nigerian obstetric population. Niger J Clin Pract. 2014;17(4):442-8.

48. Mbah AK, Sharma PP, Alio AP, Fombo DW, Bruder K, Salihu HM. Previous cesarean section, gestational age at first delivery and subsequent risk of pre-eclampsia in obese mothers. Arch Gynecol Obstet. 2012;285(5):1375-81.

49. Ventura Laveriano WR, Redondo CE. Obstetric outcomes in the second birth of women with a previous caesarean delivery: a retrospective cohort study from Peru. Rev Bras Ginecol Obstet. 2013;35(4):148-52.

50. Hemminki E, Merilainen BJ. Long-term effects of cesarean sections: ectopic pregnancies and placental problems. Am J Obstet Gynecol. 1996;174(5):1569-74.

51. van Oostwaard MF, Langenveld J, Schuit E, Papatsonis DN, Brown MA, Byaruhanga RN, Bhattacharya S, Campbell DM, Chappell LC, Chiaffarino F, et al. Recurrence of hypertensive disorders of pregnancy: an individual patient data metaanalysis. Am J Obstet Gynecol. 2015;212(5):624.e621-17.

52. Kim C, Berger DK, Chamany S. Recurrence of gestational diabetes mellitus: a systematic review. Diabetes Care. 2007;30(5):1314-9.

53. Cho GJ, Kim LY, Min KJ, Sung YN, Hong SC, Oh MJ, Seo HS, Kim HJ. Prior cesarean section is associated with increased preeclampsia risk in a subsequent pregnancy. BMC Pregnancy Childbirth. 2015;15:24.

54. Gauster M, Desoye G, Totsch M, Hiden U. The placenta and gestational diabetes mellitus. Curr Diab Rep. 2012;12(1):16-23.

55. Lee T, Carpenter MW, Heber WW, Silver HM. Preterm premature rupture of membranes: risks of recurrent complications in the next pregnancy among a population-based sample of gravid women. Am J Obstet Gynecol. 2003;188(1):209-13.

56. Wood SL, Chen S, Ross S, Sauve R. The risk of unexplained antepartum stillbirth in second pregnancies following caesarean section in the first pregnancy. BJOG. 2008;115(6):726-31.

57. Hemminki E, Shelley J, Gissler M. Mode of delivery and problems in subsequent births: a register-based study from Finland. Am J Obstet Gynecol. 2005;193(1):169-77.

58. Abenhaim HA, Benjamin A. Effect of prior cesarean delivery on neonatal outcomes. J Perinat Med. 2011:39(3):241-4.

\section{Ready to submit your research? Choose BMC and benefit from:}

- fast, convenient online submission

- thorough peer review by experienced researchers in your field

- rapid publication on acceptance

- support for research data, including large and complex data types

- gold Open Access which fosters wider collaboration and increased citations

- maximum visibility for your research: over $100 \mathrm{M}$ website views per year

At BMC, research is always in progress.

Learn more biomedcentral.com/submissions 